\title{
Successful Amelioration of Inflammatory Linear Verrucous Epidermal Nevus with Topical Sirolimus
}

\author{
Nayankumar Patel, Jignaben Padhiyar, Ani Patel, Aseem Chhibber, Tejas Patel, Bhagirath Patel \\ Department of Dermatology, Venerealogy and Leprosy, GCS Medical College, Hospital and Research Centre, Ahmedabad, India
}

\section{Dear Editor:}

Inflammatory linear verrucous epidermal nevus (ILVEN) is distinctive type of epidermal nevus characterized by intensely pruritic linear confluent, scaly, erythematous papules and plaques. For diagnosis, Altman and Mehregan clinical criteria is used which includes early age of onset, 4:1 female preponderance, frequent involvement of left lower extremity, pruritus, inflammatory linear appearance following the lines of blaschko and persistent lesions showing marked refractoriness to treatment. Similarly for histological diagnosis, Dupre and Cristol criteria mentioning hypergranulosis and parakeratosis alternating with hypogranulosis and orthokeratosis is utilized. This entity is quite resistant to various therapies including topical \& intralesional steroids, topical retinoids and cryotherapy ${ }^{1}$. Eighteen years old female presented to department of dermatology with complaint of skin lesion over right hand which had been present since her infancy. Lesion has gradually developed significant redness and itching over a period of last 8 years. On examination well defined erythematous, dry, scaly plaque involving palmer aspect of right hand with involvement of index finger, base of middle finger, ring finger and little finger. Associated reducible Swan-Neck flexure deformity of ring finger was also present (Fig. 1A, $2 \mathrm{~A}$; patient's consent for publication of images was obtained). Potassium hydroxide mount of skin scrapping was negative for any fungal element. There was no associated systemic finding. Skin biopsy from lesion revealed psoriasiform hyperplasia with alternating parakeratosis and orthokeratosis and focal hypogranulosis. Papillary dermis show- ing dilated tortuous capillaries with band like lymphohistocytic infiltrate (Fig. 2B, C).

Based on clinical and histological findings diagnosis of ILVEN was made. Patient was not willing for any ablative procedure; previous medical records showed poor response to topical steroid, retinoid and calcipotriol. Patient was offered off label use of topical sirolimus after written con-
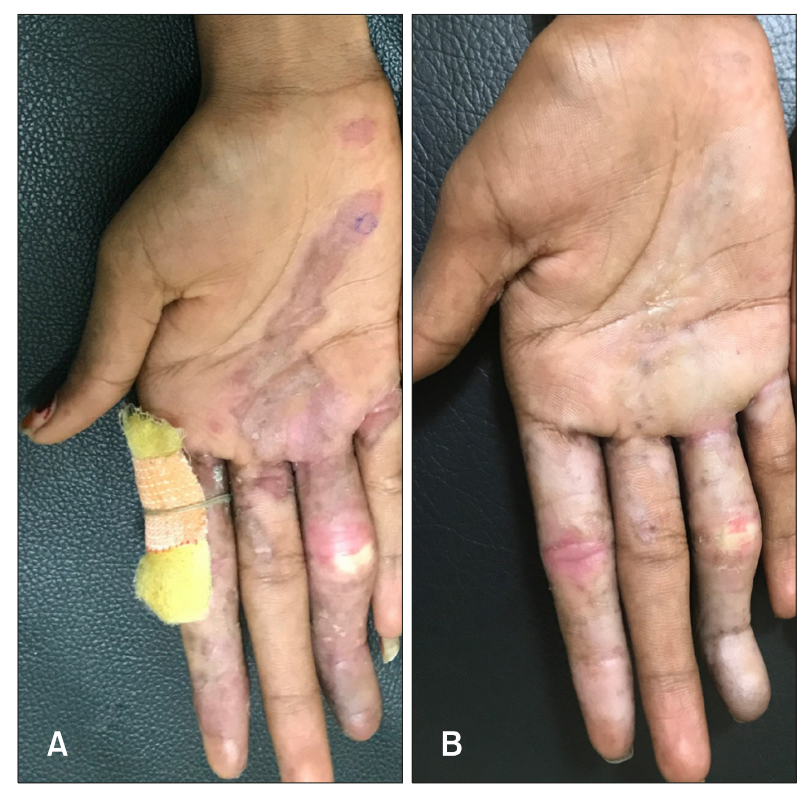

Fig. 1. (A) Inflammatory linear verrucous epidermal nevus involving right palm with reducible 'Swan-neck' deformity of ring finger. (B) Remarkable amelioration of skin lesion 3 months post starting topical sirolimus.

Received November 18, 2019, Revised December 13, 2019, Accepted for publication December 17, 2019

Corresponding author: Nayankumar Patel, Department of Dermatology, Venerealogy and Leprosy, GCS Medical College, Hospital and Research Centre, Ahmedabad 380025, India. Tel: 91-79-66048035, Fax: 91-79-66048036, E-mail: patelnayan78.np@gmail.com ORCID: https://orcid.org/0000-0001-5578-2335

This is an Open Access article distributed under the terms of the Creative Commons Attribution Non-Commercial License (http://creativecommons.org/licenses/by-nc/4.0) which permits unrestricted non-commercial use, distribution, and reproduction in any medium, provided the original work is properly cited.

Copyright $($ The Korean Dermatological Association and The Korean Society for Investigative Dermatology 

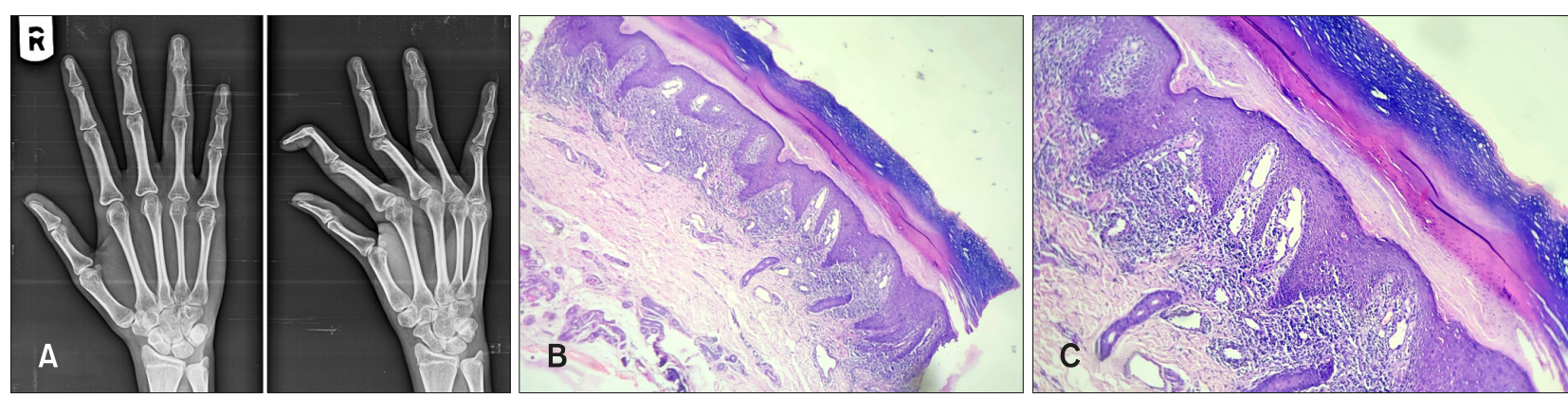

Fig. 2. (A) X-ray of involved hand ruling out underlying bone or joint involvement. (B, C) Findings of skin biopsy showing characteristic feature of inflammatory linear verrucous epidermal nevus $(B$ : $H \& E, \times 4 ; C: H \& E, \times 10)$.

sent for off label use. Based on previously published reports, topical sirolimus $0.4 \%$ was prepared by mixing 40 crushed tablets of $1 \mathrm{mg}$ sirolimus with $10 \mathrm{~g}$ white petrolatum ointment ${ }^{2}$. Patient was advised to apply 1 finger tip unit uniformly over lesion once in the evening at least 3 hours before retiring to bed and to be kept overnight. Patient was advised to avoid any work from affected hand for at least 3 hours after application. Four weeks post initiation of topical sirolimus patient achieved significant improvement in itching and skin lesion. There was remarkable amelioration of itching and skin lesion 3 months post starting topical sirolimus (Fig. 1B). At the time of writing of this report patient is under regular monthly follow-up, frequency of application of topical sirolmus has been reduced to twice a week after initial 3 months and she is maintaining clinical remission. Patient had no local or systemic adverse event throughout treatment and follow up period. Sirolimus is inhibitor of mammalian target of rapamycin protein which has antiproliferative, antiangiogenic and immunosuppressive action ${ }^{3}$. Sirolimus down regulates $\mathrm{T}$ cell proliferation and thereby various cytokine production. There is evidence of role of interleukin (IL)-1,6 and tumor necrosis factor (TNF) alpha in ILVEN ${ }^{4}$. Of late topical sirolimus is increasingly being tried in infantile haemangiomas $^{5}$, epidermal nevus ${ }^{6}$ and genodermatoses like facial angiofibromas of tuberous sclerosis ${ }^{7}$, plantar keratoderma of pachyonychia congenita. Antiproliferative, down regulation of $\mathrm{T}$ cell proliferation and resultant decrease in proinflammatory cytokines (IL-1,6 and TNF- $\alpha$ ) could be mechanism behind excellent response of topical sirolimus in our patient. Topical sirolimus has opened up a new avenue in management of difficult to treat dermatological disorders and further detailed study can provide promising future treatment option for ILVEN. Limited published literature is available for effect of sirolimus on ILVEN, our experience is based on single case report, large case series or randomized controlled study is required to draw more robust scientific inference.

\section{CONFLICTS OF INTEREST}

The authors have nothing to disclose.

\section{FUNDING SOURCE}

None.

\section{DATA SHARING STATEMENT}

The data that support the findings of this study are available from the corresponding author upon reasonable request.

\section{ORCID}

Nayankumar Patel, https://orcid.org/0000-0001-5578-2335 Jignaben Padhiyar, https://orcid.org/0000-0003-2331-3598 Ani Patel, https://orcid.org/0000-0001-9429-3040 Aseem Chhibber, https://orcid.org/0000-0002-9439-5271 Tejas Patel, https://orcid.org/0000-0002-3917-8899 Bhagirath Patel, https://orcid.org/0000-0002-5622-9205

\section{REFERENCES}

1. Rulo HF, van de Kerkhof PC. Treatment of inflammatory linear verrucous epidermal nevus. Dermatologica 1991;182: 112-114.

2. Vasani R. Topical sirolimus in the treatment of facial angiofibromas. Indian J Drugs Dermatol 2018;4:49-51.

3. Paghdal KV, Schwartz RA. Sirolimus (rapamycin): from the soil of Easter Island to a bright future. J Am Acad Dermatol 2007;57:1046-1050.

4. Welch ML, Smith KJ, Skelton HG, Frisman DM, Yeager J, Angritt $\mathrm{P}$, et al. Immunohistochemical features in inflammatory linear verrucous epidermal nevi suggest a distinctive pattern of clonal dysregulation of growth. Military Medical Consortium for the Advancement of Retroviral Research. J 
Brief Report

Am Acad Dermatol 1993;29(2 Pt 1):242-248.

5. Kaylani S, Theos AJ, Pressey JG. Treatment of infantile hemangiomas with sirolimus in a patient with PHACE syndrome. Pediatr Dermatol 2013;30:e194-e197.

6. Dodds M, Maguiness S. Topical sirolimus therapy for epidermal nevus with features of acanthosis nigricans. Pediatr
Dermatol 2019;36:554-555.

7. Cinar SL, Kartal D, Bayram AK, Canpolat $M$, Borlu M, Ferahbas A, et al. Topical sirolimus for the treatment of angiofibromas in tuberous sclerosis. Indian J Dermatol Venereol Leprol 2017;83:27-32.

\title{
Comments on "Unusual Presentation of Subcutaneous Phaeohyphomycosis by Alternaria alternate" by Lee et al.
}

\author{
Jong Bin Park, Kee Suck Suh, Min Soo Jang \\ Department of Dermatology, Kosin University College of Medicine, Busan, Korea
}

\section{Dear Editor:}

Lee et al. ${ }^{1}$ recently reported an interesting case entitled, "Unusual presentation of subcutaneous phaeohyphomycosis by Alternaria alternate."

Phaeohyphomycosis is the general term used to describe infections due to dematiaceous or darkly pigmented fungi. This is histologic definition of a disease process that can be caused by many different organisms and can have multiple different clinical presentations ${ }^{2}$. Over 100 species and 60 genera of dematiaceous fungi have been implicated in human diseases. Bipolaris, Phialophora, Alternaria, and Exophiala are the fungi responsible for phaeohyphomycosis ${ }^{2}$. The distinguishing feature of these species is presence of melanin in Athe cell walls, which imparts the dark color to their conidia or spores and hyphae. In addi-

Received November 19, 2019, Accepted for publication November 19, 2019

Corresponding author: Min Soo Jang, Department of Dermatology, Kosin University College of Medicine, 262 Gamcheon-ro, Seo-gu, Busan 49267, Korea. Tel: 82-51-990-6145, Fax: 82-51-990-3041, E-mail: ksderm77@ unitel.co.kr

ORCID: https://orcid.org/0000-0002-5686-0830

This is an Open Access article distributed under the terms of the Creative Commons Attribution Non-Commercial License (http://creativecommons. org/licenses/by-nc/4.0) which permits unrestricted non-commercial use, distribution, and reproduction in any medium, provided the original work is properly cited.

Copyright (c) The Korean Dermatological Association and The Korean Society for Investigative Dermatology tion, the colonies are typically brown to black in color. The diagnosis of phaeohyphomycosis is confirmed by histopathological examination of clinical specimens and careful gross and microscopic examination of cultures $^{3}$. In this case report, gross and microscopic findings of culture were not described. To diagnose phaeohyphomycosis by histological examination, it is necessary to identify the presence of melanin in the fungal wall. However, Fig. 2A, $B$ do not show any pigmented hyphae or spores in Hematoxylin and Eosin (H\&E)-stained sections. In Fig. 2D, the presence of melanin pigment in the fungal wall is identified only by Fontana-Masson staining. The authors have stated, "A specific melanin stain such as Fontana-Masson can be used to identify the dark pigmented fungi accurately." We would like to comment that use of Fontana-Masson melanin stain is not recommended to identify dematiaceous fungi ${ }^{1}$.

The production of melanin is not unique to dematiaceous fungi. West et al. ${ }^{4}$ used Fontana-Masson stain in tissue sections of 132 cases of culture-proven mycoses to classify the staining patterns of common fungal pathogens. Many non-dematiaceous organisms, including Zygomycetes, Aspergillus, and Fusarium in addition to Cryptococcus, showed positive results. Interestingly, only $63 \%$ cases diagnosed with dematiaceous fungi stained positive with FontanaMasson. The authors suggested that Fontana-Masson staining should not be relied upon as proof that an organism is dematiaceous. Elston ${ }^{5}$ stated, "Pigment can sometimes be 